\title{
Aberrant Expression of Cyclin D1 in Pulmonary Proliferative Lesions Induced by High Doses of Urethane in Transgenic Mice Carrying the Human Prototype c-H-ras Gene
}

\author{
Ikuo MORI ${ }^{1}$, Kazuo YASUHARA ${ }^{2)}$, Shim-mo HAYASHI ${ }^{1)}$, Takashi NONOYAMA ${ }^{1)}$, Tatsuji NOMURA ${ }^{4)}$, \\ Tokuma YANAI $^{3)}$, Toshiaki MASEGI ${ }^{3)}$ and Kunitoshi MITSUMORI ${ }^{2)}$ \\ ${ }^{1)}$ Drug Analysis and Pharmacokinetics Research Laboratories Drug Safety Research Laboratories Takeda Chemical Industries, Ltd.,2- \\ 17-85 Jusohonmachi, Yodogawa-ku, Osaka 532-8686, ${ }^{2}$ Division of Pathology, National Institute of Health Sciences, 1-18-1 Kamiyoga, \\ Setagaya-ku, Tokyo 158-8501, ${ }^{3)}$ Department of Veterinary Pathology, Gifu University 1-1 Yanagido, Gifu 501-1112, ${ }^{4)}$ Central \\ Laboratories for Experimental Animals, 1430 Nogawa, Miyamae-ku, Kawasaki 216-0001, Japan
}

(Received 5 July 2000/Accepted 8 November 2000)

\begin{abstract}
In our previous study, when rasH2 mice and non-transgenic (non-Tg) littermates were injected intraperitoneally with 1,000 $\mathrm{mg} / \mathrm{kg}$ of urethane once or three times at two-day intervals, the incidence of lung proliferative lesions in rasH2 mice given triple doses of urethane was significantly increased, compared to that in rasH2 mice given a single dose of urethane, and the mutation frequency of the transgene in lung tumors in rasH2 mice given triple doses was lower than that in rasH2 mice given a single dose of urethane. In the present study, differential immunohistochemical expressions of Cyclin D1 and PCNA, that lead to abnormal cell proliferation and tumor development due to uncontrolled G1-S transition in the cell cycle, as well as p53 tumor suppressor gene in pulmonary proliferative lesions obtained from our previous study were investigated. Over-expression of Cyclin D1 in hyperplasias in rasH2 mice given triple doses was significantly increased, compared to that in the single-injection group, but no significant differences in Cyclin D1 between the single and triple injection groups were observed in hyperplasias in non-Tg mice or lung tumors in either rasH2 or non- $\mathrm{Tg}$ mice. There were no differences in the PCNA labeling index of hyperplasias in rasH2 or non-Tg mice between the triple-injection and single-injection groups, while the PCNA labeling index tended to be increased in the tumor, compared with that in hyperplasias. There was neither mutation of $p 53$ nor an increase in immunoreactivity of wild type $p 53$ in these proliferative lesions. These results suggest that cyclin D1 over-expression in alveolar/bronchiolar hyperplasias in rasH2 mice in the triple-injection group is not only indicative of a high cell proliferation rate but also of an important role in the process of malignant transformation.

KEY WORDS: alveolar/bronchiolar tumor, cyclin D1, immunohistochemistry, rasH2 mouse, urethane.
\end{abstract}

J. Vet. Med. Sci. 63(3): 261-268, 2001

A transgenic ( $\mathrm{Tg})$ mouse carrying the human c-H-ras proto-oncogene, a rasH2 mouse, has the genetic background of $\mathrm{C} 57 \mathrm{BL} / 6 \mathrm{~J} \times \mathrm{BALB} / \mathrm{cByJ} \mathrm{F} 1$ [27]. This Tg mouse is thought to offer promise for use as an animal model in the development of a rapid carcinogenesis testing system $[5,23$, 31-33]. Urethane is a well-known mutagen and complete carcinogen that causes lung tumor at relatively large dosage such as $1,000 \mathrm{mg} / \mathrm{kg}$ in experimental animals [4, 13, 18, 24, 29]. It has been shown that rasH 2 mice are more susceptible than their non-transgenic (non-Tg) littermates to lung proliferative lesions induced by urethane [20]. In addition, Ogawa et al. reported that the transgene in lung tumors in rasH 2 mice induced by a single dose of urethane contained a point mutation at the second base of codon 61 in $80 \%$ of cases [23]. On the other hand, our previous study demonstrated that the incidence and multiplicity of lung proliferative lesions in rasH2 mice given triple-injection of 1,000 $\mathrm{mg} / \mathrm{kg}$ of urethane at two-day intervals was significantly increased, compared to that in rasH2 mice given a single dose $1,000 \mathrm{mg} / \mathrm{kg}$ of urethane, and the mutation frequency of the transgene in lung tumors in rasH 2 mice given tripleinjection of urethane was lower than that in $\mathrm{rasH} 2$ mice given a single dose [21]. However, we could not clarify the reason why the mutation frequency of the oncogene was decreased in lung proliferative lesions in rasH 2 mice by the administration of triple versus single dose of urethane.

Cyclin D1, one of the cell cycle regulatory genes $[9,10$, $22]$, is emerging as a potentially significant oncogene in lung tumors $[8,28]$. By acting in conjunction with protein kinase cdk4, cyclin D1 may initiate its own inactivation due to phosphorylation of the retinoblastoma gene product $(R b$ protein) and consequently to unhindered progression of the cell to the $S$ phase $[7,11,28,35]$. Over-expression of cyclin D1 found in several types of experimental animals and human neoplasms suggests that the inactivation of the $R b$ pathway may be an important step for tumor development [6]. In addition, cyclin D1 forms complexes with the proliferating cell nuclear antigen (PCNA) [39], which is an auxiliary protein of DNA polymerases required for DNA replication and repair.

An extremely high incidence of mutation and aberrant expression of the $p 53$ tumor suppressor gene is observed in several experimental animals and human neoplasms $[3,15$, 30, 34]. These abnormalities found in tumors at the restriction checkpoint result finally in the loss or suppression of $p R b$ function. Therefore, it is reasonable to infer that multiple disruptions of the growth-regulatory mechanisms defined by these proteins would be related to tumor proliferation and progression [35].

In the present study, we examined differential immuno- 
histochemical expression of Cyclin D1, PCNA and P53 in the pulmonary proliferative lesions in rasH2 mice induced by the administration of a single or triple-injection of urethane in our previous study [19-21].

\section{MATERIALS AND METHODS}

Male and female rasH2 mice and non-Tg littermates were injected intraperitoneally with $1,000 \mathrm{mg} / \mathrm{kg}$ of urethane once or three times at two-day intervals. Details of the experimental procedure have been published previously [21]. Briefly, five rasH2 and non-Tg mice of each sex in the single- and triple-injection groups were killed under ether anesthesia for an interim kill 10 weeks after the urethane treatment. All the surviving mice were subjected to terminal kill 15/20 weeks after single- and triple-injection urethane treatments, respectively. Lungs were embedded in paraffin, sectioned at a thickness of $4 \mu \mathrm{m}$, and subjected to routine hematoxylin and eosin staining.

Immunohistochemical staining was performed to detect expression of Cyclin D1, PCNA and P53. Formalin-fixed paraffin-embedded serial sections containing pulmonary lesions were pretreated twice by microwaving at $500 \mathrm{~W}$ in an antigen retrieval solution (BioGenex Labs., San Romon, CA, U.S.A.). After routine inhibition of endogenous peroxidase activity with $0.3 \% \mathrm{H}_{2} \mathrm{O}_{2}$, non-specific proteins were blocked with normal goat serum. Specimens were incubated with one of the following primary antibodies overnight at $4{ }^{\circ} \mathrm{C}$ : monoclonal antibody against cyclin $\mathrm{D} 1$ protein (Upstate Biolotechnology Inc., Lake Placid, NY, U.S.A.), monoclonal antibody against PCNA (PC10, DAKO Corporation, Carpinteria, CA, U.S.A.), and polyclonal antibody reactive to wild type and mutant $p 53$ protein (CM1, Novocastra Labs., Newcastle, UK). Immunolocalization was demonstrated using the streptavidin-biotin immunoperoxidase method (Nichirei Corporation, Tokyo, Japan) with diaminobenzidine as the substrate and Mayer's hematoxylin for counter staining. Selected formalin-fixed paraffinembedded sections of follicular cell carcinomas from rat thyroid glands, which are known to show over-expression of Cyclin D1 and P53 were used as positive controls. The mutation patterns of the P53 positive controls were certified by PCR single-strand conformation polymorphism (SSCP) analysis. Negative control tissues were prepared in exactly the same way as described above for each antibody, except the primary antibody was omitted and only the primary antibody-diluting buffer was used. The numbers of Cyclin D1 and PCNA positive nuclei in each lung proliferative lesion, including hyperplasias, adenomas and carcinomas, were measured using image analyzing software (KS400, Zeiss, Germany) to give percentage (\%) values.

For electron microscopy, selected tumor specimens from rasH2 mice killed at 15 weeks after triple injections were fixed in isotonically buffered ( $\mathrm{pH}$ 7.4) glutaraldehyde, postfixed in $1.0 \%$ osmium tetroxide and embedded in epoxy resin. Ultra-thin sections were doubly stained with uranyl acetate and citrate and observed under a JEM-1200EX electron microscope (JEOL, Tokyo, Japan).

The data on the percentage of Cyclin D1 and PCNA positive cells in lung proliferative lesions were analyzed by Student's $t$-test. Intergroup differences were compared between the single- and triple-injection groups.

\section{RESULTS}

The incidences of lung proliferative lesions in rasH2 mice treated with urethane are summarized in Table 1. Alveolar/ bronchiolar hyperplasias and adenomas of the lung were observed in all animals in each group from week 10, and carcinomas were observed in male and female rasH2 mice in the triple-injection group from week 10 and in female non-Tg mice in the single-injection group at 15/20 weeks.

Histopathologically, tumors induced in rasH 2 mice by the treatment with urethane were classified as alveolar/bronchiolar hyperplasias, adenomas or carcinomas. Alveolar/bronchiolar hyperplasias were composed of cuboidal to columnar epithelial cells arranged in papillary or glandular patterns overlying a delicate fibrovascular stroma (Fig. 1).

Table 1. Incidence of lung proliferative lesions induced by urethane in rasH2 and non-Tg mice

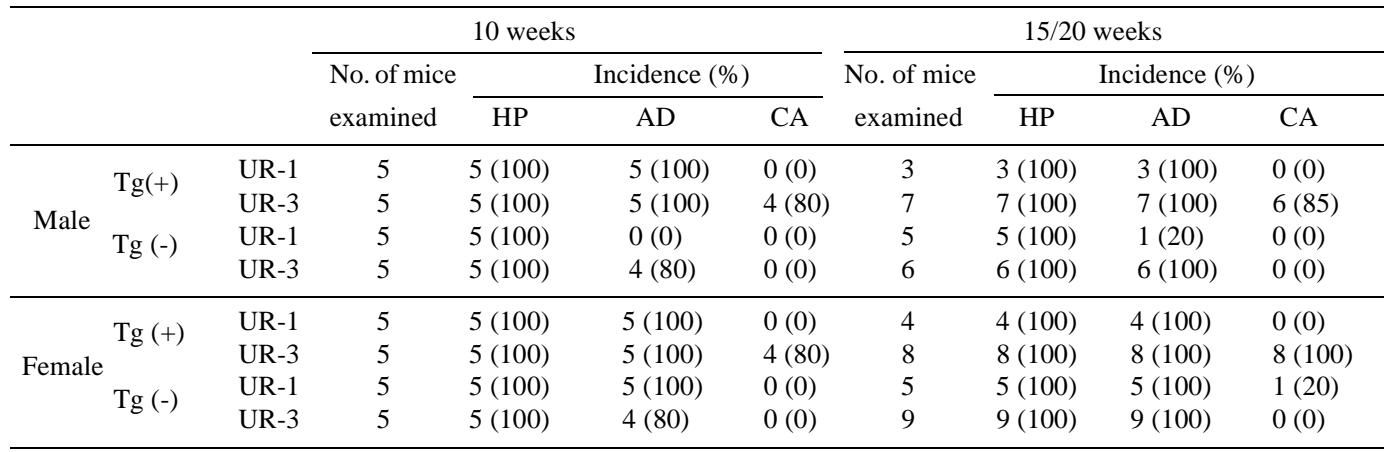

$\operatorname{Tg}(+)$ : Transgenic mice carrying human c-H-ras genes, $\operatorname{Tg}(-)$ : non-transgenic mice.

$\mathrm{HP}$ : Alveolar/bronchiolar hyperplasia, $\mathrm{AD}$ : adenoma, $\mathrm{CA}$ : carcinoma

UR-1: Subjected to a single injection of $1,000 \mathrm{mg} / \mathrm{kg}$ urethane.

UR-3: Subjected to triple-injection of $1,000 \mathrm{mg} / \mathrm{kg}$ urethane. 


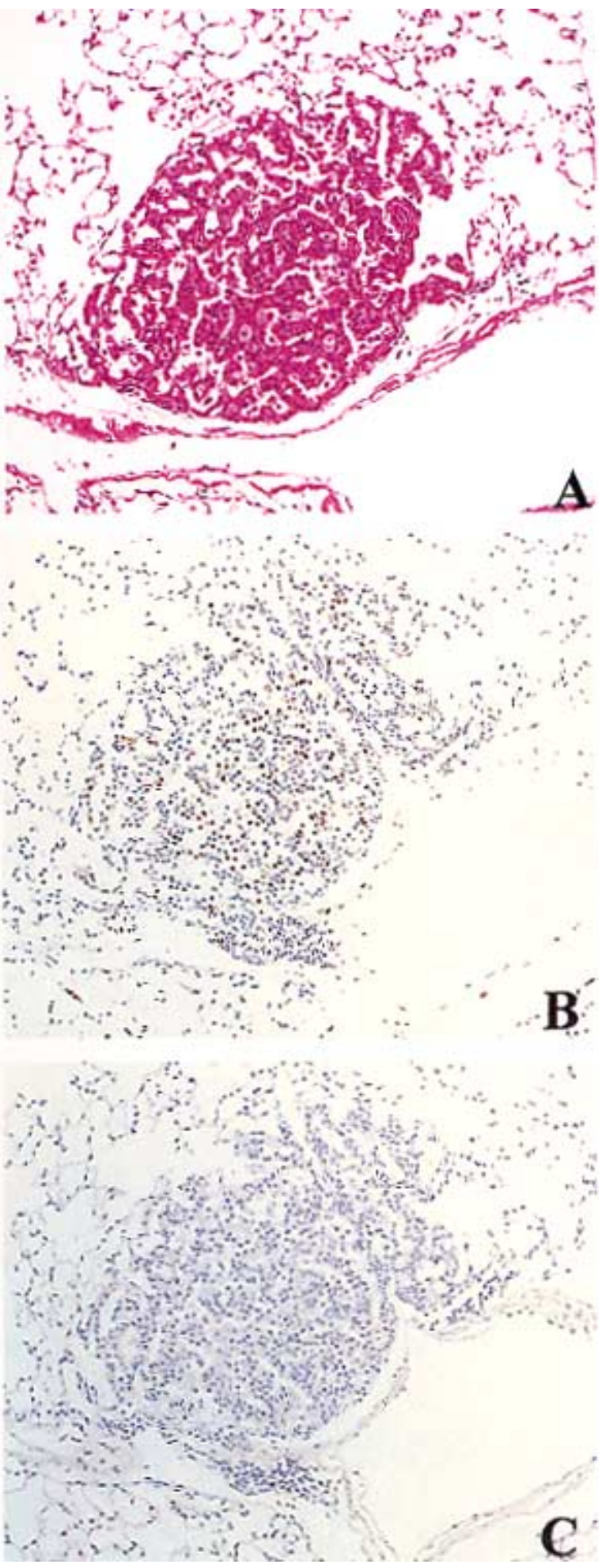

Fig. 1. Histopathological appearance of an alveolar/bronchiolar hyperplasia characterized by papillary/glandular growth of cuboidal to columnar epithelial cells that was observed in a male rasH2 mouse killed 10 weeks after a single injection of
The cuboidal cells were relatively uniform with round to oval nuclei and moderately abundant cytoplasm. In alveolar/bronchiolar adenomas showing papillary growth, prominent projections into alveolar spaces were characteristic (Fig. 2). With alveolar/bronchiolar adenomas showing glandular patterns, tumor cells lining the alveolar walls exhibited prominent tubular profiles. Alveolar/bronchiolar carcinomas demonstrated a mixed cellular pattern, showing papillary and glandular as well as solid growth at different sites (Fig. 3). Tumor cells in areas showing papillary growth grew on a fine fibrovascular stroma, and those showing glandular patterns were evident as nests or acini. The solid tumors were characterized by solid growth of cuboidal or rounded cells with little stroma. Pleomorphic and anaplastic spindle-shaped cells were also observed in these tumors.

Immunohistochemically, over-expression of Cyclin D1 was localized within the nuclei of cells forming lung proliferative lesions. Representative cases are shown in Figs. 1B, $2 \mathrm{~B}$ and $3 \mathrm{~B}$. Normal lung tissue such as that made up of broncho-alveolar cells was not stained, while a few broncho-epithelial cells were stained, corresponding to a Cyclin D1 index of less than $1 \%$. The positive expression rates of hyperplasias in the single- and triple-injection groups were $19.7 \pm 12.8$ and $46.3 \pm 12.2$ in male rasH2 mice and $18.4 \pm$ 9.8 and $43.6 \pm 13.3$ in female rasH2 mice at week 10 , respectively, and $17.8 \pm 14.5$ and $42.1 \pm 13.1$ in male rasH2 mice and $15.8 \pm 8.2$ and $40.1 \pm 12.4$ in female rasH 2 mice at week $15 / 20$, respectively. The positive expression rates of hyperplasias in rasH2 mice of both sexes at week 10 and 15/ 20 in the triple-injection group were significantly higher than these in the single-injection group. No significant differences were observed in hyperplasias in non-Tg mice or adenomas in either rasH2 or non- $\mathrm{Tg}$ mice of either sex (Table 2).

A positive immunoreaction for PCNA was obtained in each proliferative lesion (Figs. 1C, 2C and 3C). The PCNA labeling index tended to be increased with tumor transformation from hyperplasias (Table 3). These lung proliferative lesions in rasH2 and non-Tg mice of both sexes given single- and triple-injection were evaluated for immunoreactivity against $p 53$ proteins, but there were no immunoreactive cells in any of the lesions examined.

Electron microscopic observation of alveolar/bronchiolar carcinomas in male ras $\mathrm{H} 2$ mice given triple-injection of urethane revealed that most of the tumor cells had microvilli on their free surface and numerous large lamellar bodies in their cytoplasm which are characteristics of alveolar type 2 cells (Fig. 4). urethane. H\&E stain, magnification, $\times 25$ (A); Immunohistochemical staining for Cyclin D1, magnification, $\times 25$ (B); Immunohistochemical staining for PCNA, magnification, $\times 25(\mathrm{C})$. 

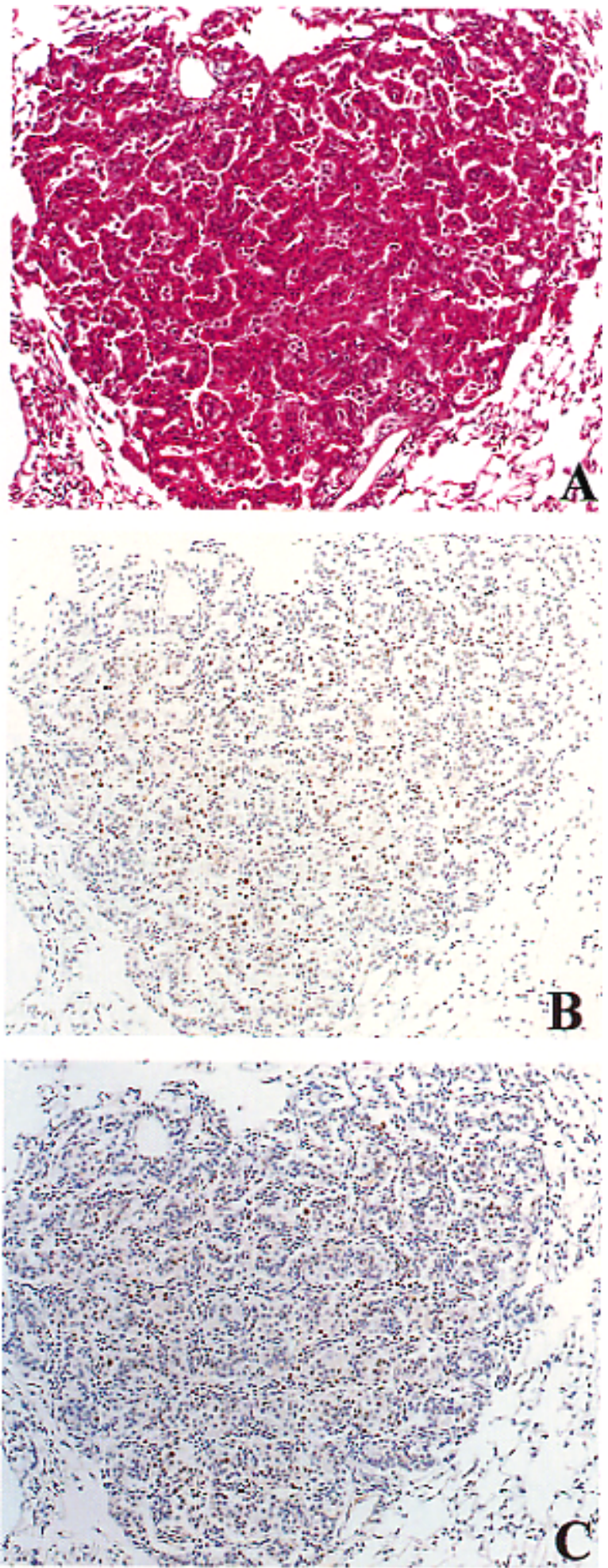

Fig. 2. Histopathological appearance of an alveolar/bronchiolar adenoma characterized by papillary/glandular growth of cuboidal tumor cells and slight compression of surrounding alveolar parenchyma that was observed in a male rasH2 mouse killed 15

\section{DISCUSSION}

Tg mice carrying the human c-H-ras proto-oncogene, rasH2 mice, are generally much more susceptible to both mutagenic and nonmutagenic carcinogens than control non$\mathrm{Tg}$ mice [31]. In our previous study, rasH2 mice were found to be very susceptible to lung proliferative lesion induction by urethane [20], and after triple-injection with urethane, lung proliferative lesions developed in all of the treated $\mathrm{rasH} 2$ mice. However, the mutation frequencies of both the transgene and mouse c-Ki-ras gene were not increased [21]. Lung proliferative lesions have been frequently induced in rasH2 mice after administration of a variety of carcinogens, including $N, N^{\prime}$-diethylnitrosamine, 4-( $N$-methyl- $N$-nitrosamino)-1-(3-pyridyl)-1-butanone, phenacetin, 4,4'-thiodianiline, vinyl carbamate and benzene [19, 20, 31-33]. The incidence of alveolar/bronchiolar adenomas and/or carcinomas in these chemically treated rasH2 mice is significantly higher than that in corresponding non- $\mathrm{Tg}$ mice. However, incidences of transgene and murine c-Ki-ras gene mutations in these carcinogen-induced lung lesions are very low [33]. These data suggest that point mutations of the transgene and murine c-Ki-ras gene do not play a major role in lung tumor induction by various carcinogens.

Cyclin D1 forms complexes with other proteins including proliferating cell nuclear antigen (PCNA) [39], which is an auxiliary protein of DNA polymerases required for DNA replication and repair. In our study, the PCNA labeling index in alveolar/bronchiolar hyperplasias in rasH2 mice in the triple-injection group was increased with the malignant transformation, and the Cyclin D1 labeling index was also significantly increased. Over-expression of Cyclin D1 in pre-malignant lesions has been reported in rodents $[16,25$, $26,38]$ and humans $[1,12]$. It thus appears that over-expression of Cyclin D1 is a common and presumably important event that occurs in the early stages of carcinogenesis in many tissues including the lung of rasH2 mice. In immunohistochemical examinations, aberrant over-expression of Cyclin D1 was observed in alveolar/bronchiolar hyperplasias in rasH2 mice in the triple-injection group, and aberrant high Cyclin D1 and PCNA labeling indices were noted in alveolar/bronchiolar adenomas and carcinomas in rasH2 and non- $\mathrm{Tg}$ mice, irrespective of the frequency of the treatment of urethane.

It has been reported that a good correlation between the presence of $p 53$ missense mutations and nuclear reactivity in the majority of tumor cells exists for various tumors in humans and that polyclonal antibodies to $p 53$ provide a more consistent indicator of the presence of mutant protein than monoclonal antibodies $[15,36]$. However, the present study indicates that there is neither mutation of $p 53$ nor an increase in immunoreactivity of wild type $p 53$ in these pro-

weeks after triple-injection of urethane. $\mathrm{H} \& \mathrm{E}$ stain, magnification, $\times 25$ (A); Immunohistochemical staining for Cyclin D1, magnification, $\times 25(\mathrm{~B})$; Immunohistochemical staining for PCNA, magnification, $\times 25(\mathrm{C})$. 

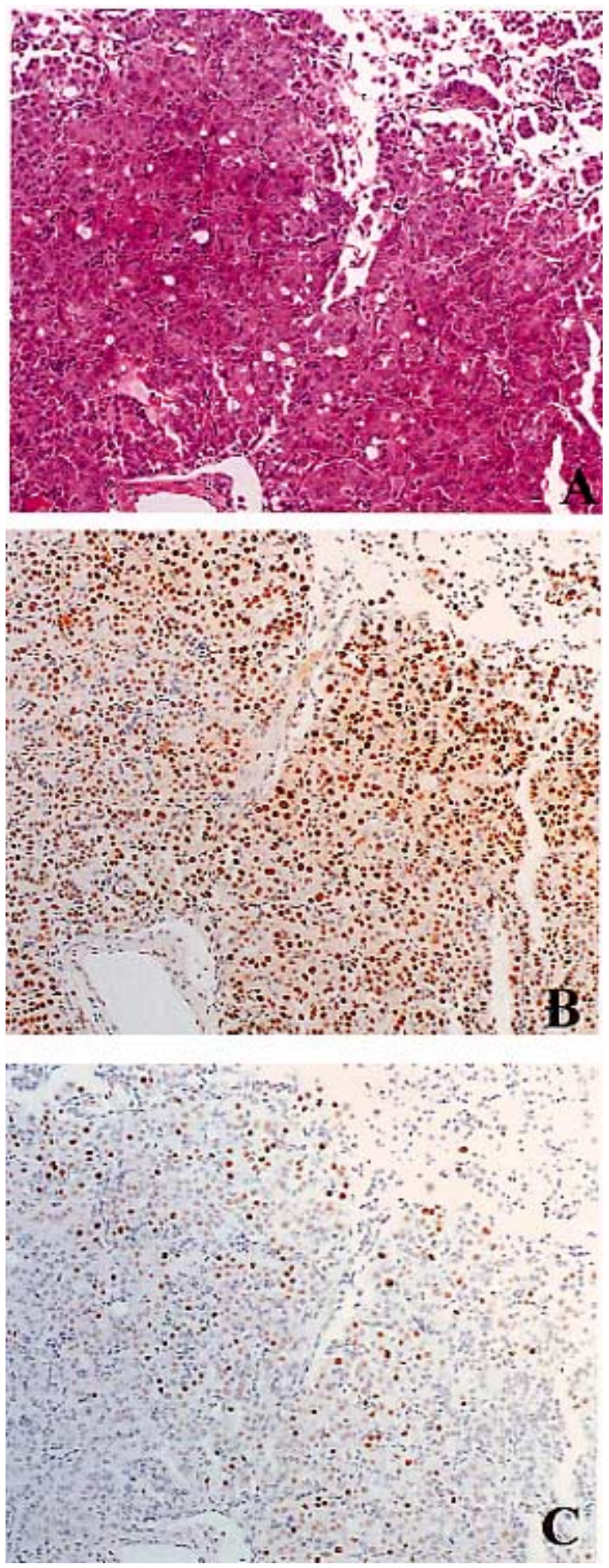

Fig. 3. Histopathological appearance of an alveolar/bronchiolar carcinoma, characterized by solid/papillary growth of pleomorphic and basophilic tumor cells, observed in a male rasH2 mouse killed 15 weeks after triple-injection of urethane. H\&E stain; magnification, $\times 25$ (A), Immunohistochemical staining liferative lesions associated with tumor development. The p53 gene product exerts its regulatory function on the cell cycle through the $p 21 / W A F 1$ protein, which has an inhibitory effect on the Cyclin D1/Cyclin dependent kinase 4 (cdk4) complex [7]. This complex is responsible for the G1/ $\mathrm{S}$ transition by phosphorylation of the $R b$ protein. High levels of Cyclin D1 result in a shorter G1 phase and may also contribute to carcinogenesis [14]. Amplification and overexpression of Cyclin D1 are observed in some experimental animals and human tumors and are associated with poor prognosis in patients with these tumors [2, 17, 37]. However, our results suggest that the $p 53$ protein is not important for the modulation of the Cyclin D1 protein in the lung carcinogenesis observed in rasH2 mice.

In conclusion, the data from the present study suggest that Cyclin D1 over-expression in alveolar/bronchiolar hyperplasias in rasH2 mice in the triple-injection group is not only indicative of a high cell proliferation rate but also of an important role in the process of malignant transformation.

ACKNOWLEDGMENT. We would like to thank Mr. J. Hogan for help in preparing the manuscript.

\section{REFERENCES}

1. Arber, N., Hibshoosh H., Moss, S. F., Sutter, T., Zhang, Y., Begg, M., Wang, S., Weinstein, I. B. and Holt, P. R. 1996. Increased expression of cyclin D1 is an early event in multistage colorectal carcinogenesis. Gastroenterology 110: 669674.

2. Buckley, M. F., Sweeney, K. J., Hamilton J. A., Sini R. L., Manning, D. L., Nicholson R. I., deFazio, A., Watts, C.K., Musgrove, E. A. and Sutherland R. L. 1993. Expression and amplification of cyclin genes in human breast cancer. Oncogene 8: 2127-2133.

3. Cazorla, M., Hernandez, L., Fernandez, P. L., Fabra, A, Peinado, M. A., Dasenbrock, C., Tillmann, T., Kamino, K., Campo, E., Kohler, M., Morawieltz, G., Cardesa, A., Tomatis, L. and Mohr, U. 1998. Ki-ras gene mutations and absence of $p 53$ gene mutations in spontaneous and urethane-induced early lung lesions in CBA/J mice. Mol. Carcinog. 21: 251-260.

4. Dahl, G. A., Miller, J. A. and Miller, E. C. 1978. Vinyl carbamate as a promutagen and a more carcinogenic analog of ethyl carbamate. Cancer Res. 38: 3793-3804.

5. Doi, S-T., Kimura, M. and Katsuki, M. 1994. Site-specific mutation of the Human c-Ha-ras transgene induced by dimethylbenzanthracene causes tissue-specific tumors in mice. Jpn. J. Cancer Res. 85: 801-807.

6. Donnellan, R. and Chetty, R. 1998. Cyclin D1 and human neoplasia. Mol. Pathol. 51: 1-7.

7. el-Deiry, W. S., Tokino, T., Velculescu, V. E., Levy, D. B., Parsons, R., Trent, J. M., Lin, D., Mercer, W. E., Kinzler, K.W. and Vogelstein, B. 1993. WAF1, a potential mediator of $p 53$ tumor suppression. Cell 75: 817-825.

8. Hayashi, S., Mitsumori, K., Yasuhara, K., Mori, I., Imazawa, T., Onodera, H., Nonoyama, T., Takahashi, M. and Hayashi, Y.

for Cyclin D1, magnification, $\times 25$ (B); Immunohistochemical staining for PCNA; magnification, $\times 25(\mathrm{C})$. 
Table 2. Percentage of Cyclin D1 positive cell of lung proliferative lesions induced by urethane in rasH2 and non-Tg mice

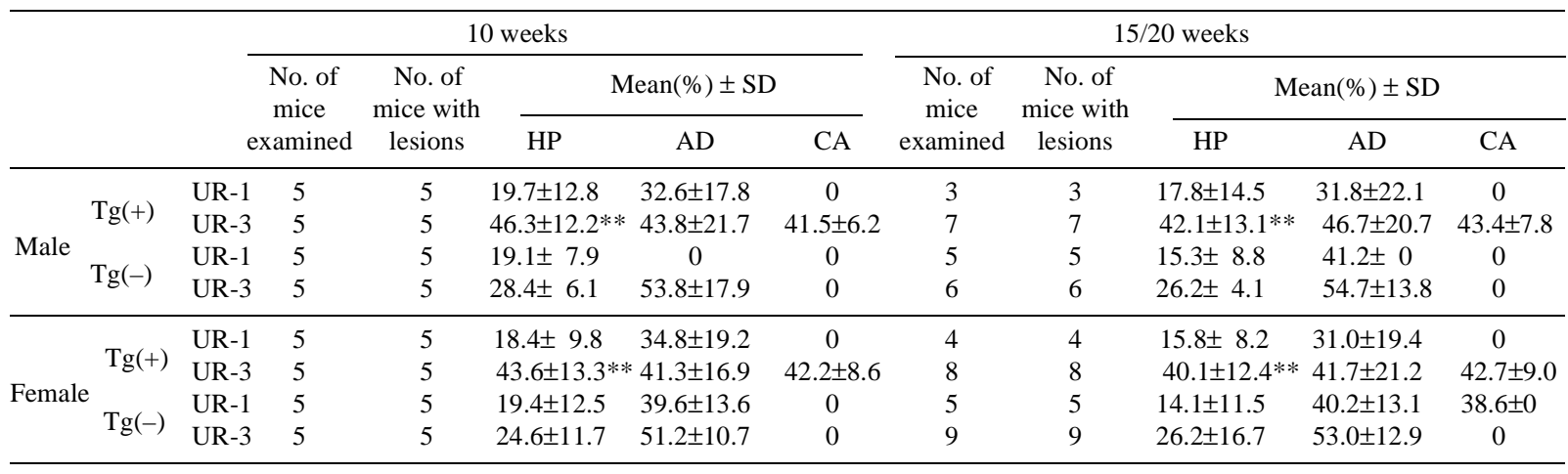

$\mathrm{Tg}(+)$ : Transgenic mice carrying human c-H-ras genes, $\mathrm{Tg}(-)$ : non-transgenic mice.

HP : Alveolar/bronchiolar hyperplasia, AD : adenoma, CA : carcinoma

UR-1: Subjected to a single injection of $1,000 \mathrm{mg} / \mathrm{kg}$ urethane.

UR-3: Subjected to triple-injection of $1,000 \mathrm{mg} / \mathrm{kg}$ urethane.

*, ** Significantly different from UR-1 group at $\mathrm{p}<0.05$ and $\mathrm{p}<0.01$, respectively.

Table 3. Percentage of PCNA positive cell of lung proliferative lesions induced by urethane in rasH2 and non- $\mathrm{Tg}$ mice

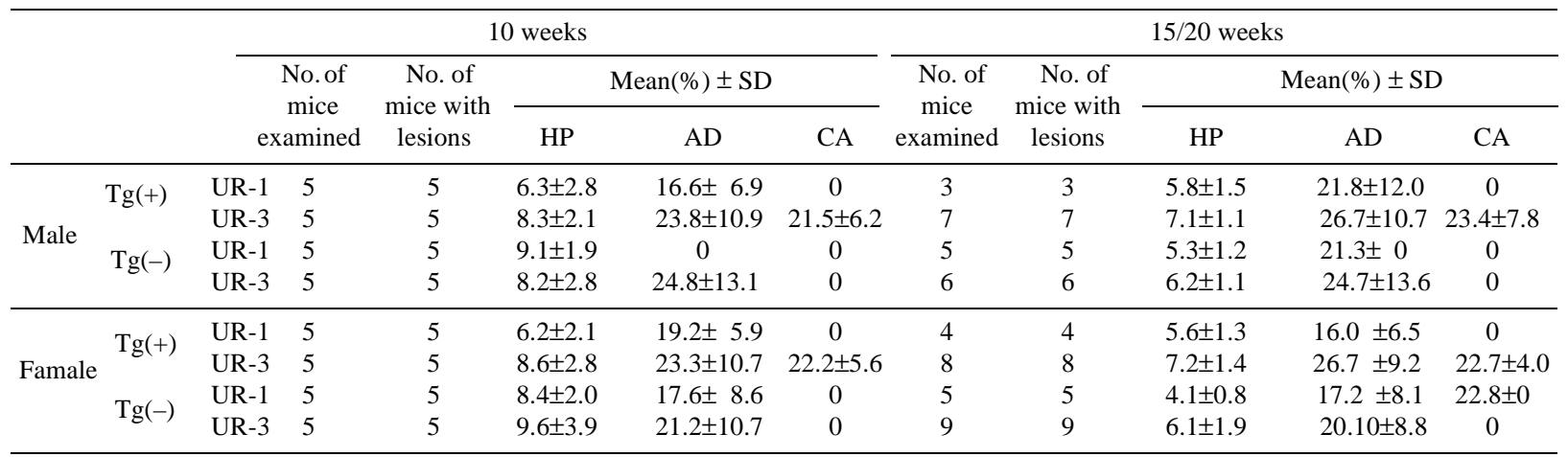

$\mathrm{Tg}(+)$ : Transgenic mice carrying human c-H-ras genes, $\mathrm{Tg}(-)$ : non-transgenic mice.

HP : Alveolar/bronchiolar hyperplasia, AD : adenoma, CA : carcinoma

UR-1: Subjected to a single injection of $1,000 \mathrm{mg} / \mathrm{kg}$ urethane.

UR-3: Subjected to triple-injection of $1,000 \mathrm{mg} / \mathrm{kg}$ urethane.

1997. Significance of cyclin D1 overexpression and K-ras point mutations in lung tumors induced by $N$-methyl- $N$ nitrosourthane in hamsters. J. Toxicol. Pathol. 10: 137-143.

9. Hunter, T. and Pines, J. 1994. Cyclins and cancer II: cyclin D and cdk inhibitors come of age. Cell 79: 573-582.

10. Jacks, T. and Weinberg, R. A. 1996. Cell-cycle control and its watchman. Nature (Lond.) 381: 643-644.

11. Jiang, W., Kahn, S. M., Zhou, P., Zhang, Y. J., Cacace, A. M., Infante, A. S., Doi, S., Santella, R. M. and Weinstein, I. B. 1993. Overexpression of cyclin D1 in rat fibroblasts causes abnormalities in growth control, cell cycle progression and gene expression. Oncogene 8: 3447-3457.

12. Kurasono, Y., Ito. T., Kameda, Y., Nakamura, N and Kitamura, H. 1998. Expression of cyclin D1, retinoblastoma gene protein, and p16 MTS1 protein in atypical adenomatous hyperplasia and adenocarcinoma of the lung. An immunohistochemical analysis. Virchows Arch. 432: 207-215.

13. Leithauser, M. T., Leim, A., Stewart, B. C., Miller, E. C. and Miller, J. A. 1990. 1, $N^{6}$-Ethenoadenosine formation, mutagenicity and murine tumor induction as indicators of the genera- tion of an electrophilic epoxide metabolite of the closely related carcinogens ethyl carbamate (urethane) and vinyl carbamate. Carcinogenesis 11: 463-473.

14. Lukas, J., Pagano, M., Staskova, Z., Draetta G. and Bartek, J. 1994. CyclinD1 protein oscillates and is essential for cell cycle progression in human tumour cell lines. Oncogene 9: 707-718.

15. Maestro, R., Dolcetti, R., Gasparotto, D., Doglioni, C., Pelucchi, S., Barzan, L., Grandi, E. and Boiocchi, M. 1992. High frequency of $p 53$ gene alterations associated with protein overexpression in human squamous cell carcinoma of the larynx. Oncogene 7: 1159-1166.

16. Malkinson, A. M. 1998. Molecular comparison of human and mouse pulmonary adenocarcinomas. Exp. Lung Res. 24: 541555 .

17. Michalides, R., van Veelen, N., Hart, A., Loftus, B., Wientjens, E. and Balm, A. 1995. Overexpression of cyclin D1 correlates with recurrence in a group of forty-seven operable squamous cell carcinomas of the head and neck. Cancer Res. 55: 975978.

18. Mirvish, S. S. 1968. The carcinogenic action and metabolism 


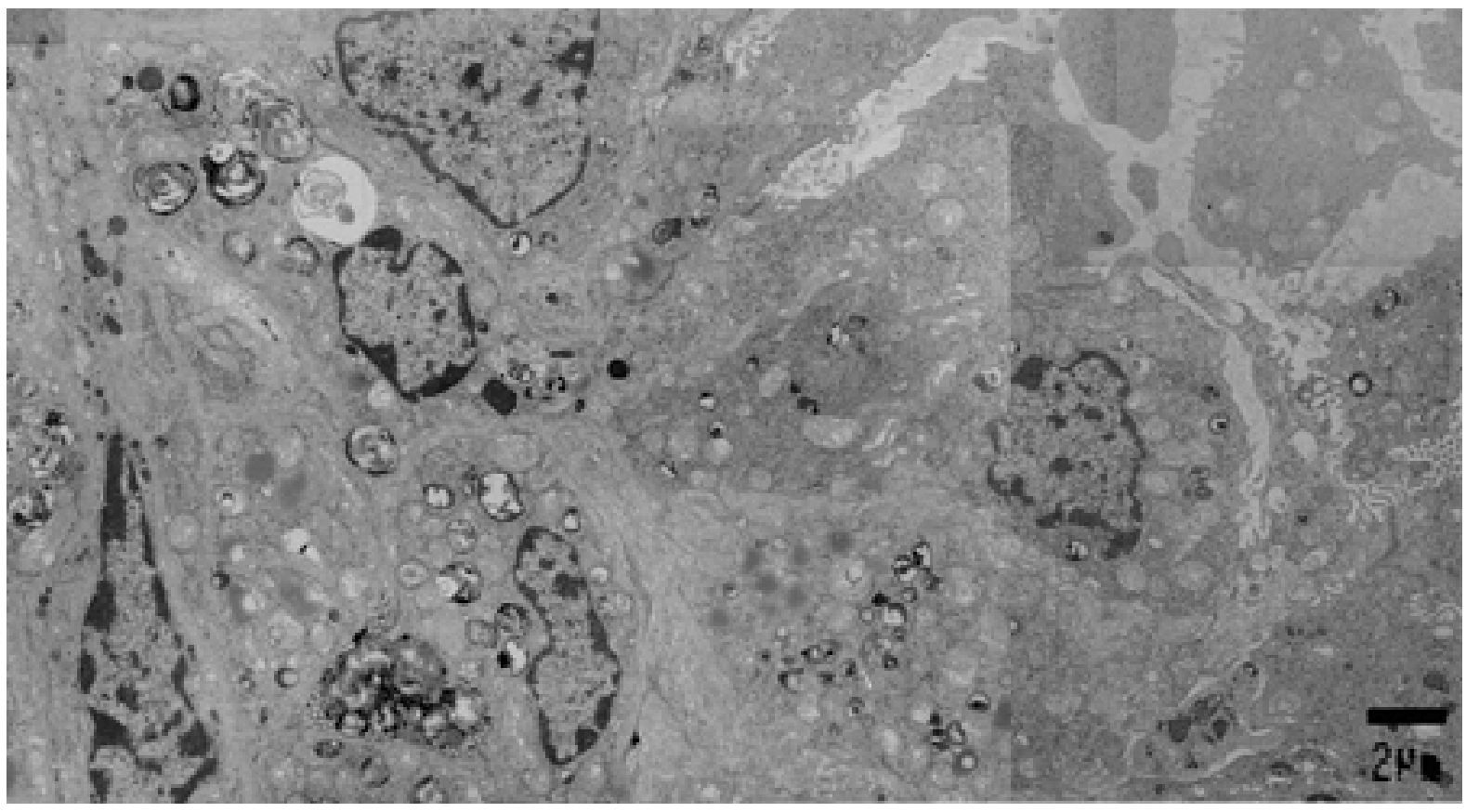

Fig. 4. Electron microscopic appearance of a lung alveolar/bronchiolar cell tumor in a rasH2 $\mathrm{Tg}$ mouse killed at 15 weeks after tripleinjection of urethane. Most of the tumor cells have microvilli on their free surface and numerous large lamellar bodies in their cytoplasm, which are characteristics of alveolar type 2 cells. Uranyl acetate and lead citrate stain, $\mathrm{Bar}=2 \mu \mathrm{m}$.

of urethan and $N$-hydroxyurethan. Adv. Cancer Res. 11: 1-42.

19. Mitsumori, K., Wakana, S., Yamamoto, S., Kodama, Y., Yasuhara, K., Nomura, T., Hayashi, Y. and Maronpot, R. R. 1997. Susceptibility of transgenic mice carrying human prototype cHa-ras gene in a short-term carcinogenicity study of vinyl carbamate and ras gene analyses of the induced tumors. Mol. Carcinog. 20: 298-307.

20. Mitsumori, K., Yasuhara, K., Mori, I., Hayashi, S., Shimo, T., Onodera, H., Nomura, T. and Hayashi, Y. 1998. Pulmonary fibrosis caused by $N$-methyl- $N$-nitrosourethane inhibits lung tumorigenesis by urethane in transgenic mice carrying the human prototype c-Ha-ras gene. Cancer Lett. 129: 181-190.

21. Mori, I., Yasuhara, K., Hayashi, S., Nonoyama T., Nomura T. and Mitsumori, K. 2000. Carcinogen dose-dependent variation in the transgene mutation spectrum in urethane-induced lung tumors in transgenic mice carrying the human prototype c-Haras gene. Cancer Lett. 153: 199-209.

22. Nurse, P. 1994. Ordering S phase and M phase in the cell cycle. Cell 79: 547-550.

23. Ogawa, K., Imaida, K., Matsui, T., Kawabe, M., Hasegawa, R., Kato, K., Ito, N. and Shirai, T. 1996. Chemically induced lung and forestomach neoplasias in transgenic mice carry mutant forms of the human c-Ha-ras transgene. Carcinogenesis 17: 341-345.

24. Park, K. K., Liem, A., Stewart, B. C. and Miller, J. A. 1993. Vinyl carbamate epoxide, a major strong electrophilic, mutagenic and carcinogenic metabolite of vinyl carbamate and ethyl carbamate (urethane). Carcinogenesis 14: 441-450.

25. Robles, A. I. and Conti C. J. 1995. Early overexpression of cyclin D1 protein in mouse skin carcinogenesis. Carcinogenesis 16: 781-786.
26. Romach, E. H., Goldsworthy, T. L., Maronpot, R. R. and Fox, T.R. 1997. Altered gene expression in spontaneous hepatocellular carcinomas from male B6C3F1 mice. Mol. Carcinog. 19: 31-38.

27. Saitoh, A., Kimura, M., Takahashi, R., Yokoyama, M., Nomura, T., Izawa, M., Sekiya, T., Nishimura, S. and Katsuki, M. 1990. Most tumors in transgenic mice with human c-Ha-ras gene contained somatically activated transgenes. Oncogene 5: $1195-1200$.

28. Sherr, C. J. 1994. G1 phase progression: cycling on cue. Cell 79: 551-555.

29. Svensson, K. 1998. Alkylation of protein and DNA in mice treated with urethane. Carcinogenesis 9: 2197-2201.

30. Tam, A. S., Foley, J. F., Devereux, T. R., Maronpot, R. R. and Massey, T.E. 1999. High frequency and heterogeneous distribution of $p 53$ mutations in aflatoxin B1-induced mouse lung tumors. Cancer Res. 59: 3634-3640.

31. Yamamoto, S., Mitsumori, K., Kodama, Y., Matsunuma, N., Manabe, S., Okamiya, H., Suzuku, H., Fukuda, T., Sakamaki, Y., Sunaga, M., Nomura,G., Hioki, K., Wakana, S., Nomura, T. and Hayashi, Y. 1996. Rapid induction of more malignant tumors by various genotoxic carcinogens in transgenic mice harboring a human prototype c-Ha-ras gene than in control non-transgenic mice. Carcinogenesis 17: 2455-2461.

32. Yamamoto, S., Hayashi, Y., Mitsumori, K. and Nomura, T. 1997. Rapid carcinogenicity testing system with transgenic mice harboring human prototype c-HRAS gene. Lab. Anim. Sci. 47: 121-126.

33. Yamamoto, S., Urano, K., Koizumi, H., Wakana, S., Hioki, K., Mitsumori, K., Kurokawa, Y., Hayashi, Y. and Nomura, T. 1998. Validation of transgenic mice carrying the human proto- 
type c-Ha-ras gene as a bioassay model for rapid carcinogenicity testing. Environ. Health Perspect. 106 (Suppl. 1): 57-69.

34. Yoshitsugu, H., Chen, A., Rice, P., Roth, J. A., Malkinson, A. M. and Schrump, D. S. 1996. Ki-ras and p53 mutations are early and late events, respectively, in urethane-induced pulmonary carcinogenesis in A/J mice. Mol. Carcinog. 17: 217-223.

35. Weinberg, R. A. 1995. The retinoblastoma protein and cell cycle control. Cell 81: 323-330.

36. Wolf, D. C., Gross, E. A., Lyght, O., Bermudez, E., Recio L. and Morgan, K. T. 1995. Immunohistochemical localization of p53, PCNA, and TGF-alpha proteins in formaldehyde-induced rat nasal squamous cell carcinomas. Toxicol. Appl. Pharmacol. 132: $27-35$.
37. Zhang, T., Nanney, L. B., Luongo, C., Lamps, L., Heppner, K. J., DuBois, R. N. and Beauchamp, R. D. 1997. Concurrent overexpression of cyclin D1 and cyclin-dependent kinase 4 (Cdk 4) in intestinal adenomas from multiple intestinal neoplasia (Min) mice and human familial adenomatous polyposis patients. Cancer Res. 57: 169-175.

38. Zhou, P., Jiang, W., Zhang, Y. J., Kahn S. M., Schieren, I., Santella, R. M. and Weinstein, I. B. 1995. Antisense to cyclin D1 inhibits growth and reverses the transformed phenotype of human esophageal cancer cells. Oncogene 11: 571-580.

39. Xiong, Y., Zhang, H. and Beach, D. 1992. D type cyclins associate with multiple protein kinases and the DNA replication and repair factor PCNA. Cell 71: 505-514. 